\title{
PERSPECTIVAS HERMENÊUTICAS DO ROMANCE METAFICCIONAL CORDILHEIRA, DE DANIEL GALERA
}

\author{
Bianca Cardoso Batista ${ }^{1}$ \\ Eunice T. Piazza Gai ${ }^{2}$
}

\begin{abstract}
Resumo: Este artigo objetiva elucidar os conceitos e características da hermenêutica, segundo Alfredo Bosi e Richard Palmer, e da metaficção, segundo Linda Hutcheon, Patrícia Waugh e Gustavo Bernardo. A partir das considerações e do posicionamento hermenêutico adotado, será feita uma pesquisa acerca da vida e obra de Daniel Galera para entender o contexto no qual o livro Cordilheira foi escrito e também para que se possa obter uma interpretação aprofundada da obra. Nesta análise é possível identificar a metaficção que, segundo Linda Hutcheon, é uma "ficção sobre ficção". Ao final do artigo pode-se concluir que o leitor que desconhece o posicionamento hermenêutico e a visão metaficcional não consegue captar o sentido do texto. A interpretação requer um leitor específico, empenhado e entregue à obra, por isso o texto metaficcional só se torna compreensível e, consequentemente, interessante, a um leitor mais preparado.
\end{abstract}

Palavras-chave: Hermenêutica. Metaficção. Cordilheira. Daniel Galera.

\begin{abstract}
This article aims to clarify the concepts and characteristic of hermeneutics, according to Alfredo Bosi and Richard Palmer, and metafiction as Linda Hutcheon, Patricia Waugh and Gustavo Bernardo. From considerations and the hermeneutic position adopted, a research about the life and work of Daniel Galera will be made to understand the context in which the book Cordilheira was written and also so you can get an in-depth interpretation of the work. In this analysis it is possible to identify the metafiction that, according to Linda Hutcheon, is a "fiction about fiction." At the end of the article can be concluded that the reader doesn't know the hermeneutic positioning and metaficional vision can not grasp the meaning of the text. The interpretation requires a specific reader engaged and delivered to the work, so metafictional text only becomes understandable and therefore interesting to a player over cooked.
\end{abstract}

Keywords: Hermeneutical. Metafiction. Cordilheira. Daniel Galera.

\section{INTRODUÇÃO}

O presente estudo vincula-se ao projeto de pesquisa Narrativas $e$ conhecimento: especificidades teóricas e constituição de sentido, coordenado

\footnotetext{
${ }^{1}$ Graduanda em Comunicação Social, habilitação em Jornalismo, da UNISC. Bolsista de IC/FAPERGS do Mestrado em Letras da UNISC. Orientadora Prof. ${ }^{a}$ Dr. ${ }^{a}$ Eunice T. Piazza Gai. E-mail: bianca_cb4@hotmail.com

${ }^{2}$ Doutora em Linguística e Letras pela PUCRS. Docente e Coordenadora do Programa de Pósgraduação - Mestrado em Letras da UNISC.
} 
pela Prof. a Dra. Eunice Terezinha Piazza Gai. O projeto tem como eixos centrais a reflexão sobre as possibilidades de relação entre narrativas literárias e conhecimento, a realização de estudos sobre a hermenêutica e a leitura, a análise e a interpretação de narrativas literárias. Estas são selecionadas a partir da presença da metaficção.

A partir disso, o artigo se construirá através das acepções teóricas acerca da hermenêutica a fim de compreender o posicionamento do leitor diante do texto visando a interpretá-lo. A adoção de um posicionamento hermenêutico diante da obra permite identificar a presença da metaficção, que é uma ficção sobre ficção, ou seja, é um elemento estético autorreferente no qual a ficção cria outras ficções, duplica-se. Após a teorização acerca dos conceitos de hermenêutica e metaficção, procede-se à interpretação do romance Cordilheira, de Daniel Galera. Mas antes disso, o texto irá debruçar-se sobre a vida e bibliografia de Daniel Galera, a fim de construir um contexto para a obra que então será observada e interpretada. Além de um resumo de Cordilheira, este estudo pretende apresentar os diversos fragmentos em que a metaficção se evidencia na obra.

\section{PRESSUPOSTOS HERMENÊUTICOS}

A hermenêutica é um processo de interpretação que, segundo Bosi, consiste num olhar mais intenso e demorado sobre a obra, ou seja, trata-se do procedimento de compreensão que capta o mais puro significado do texto. Esse processo de interpretação se faz necessário visto que as palavras não são diáfanas, ou seja, mesmo quando possuem forte expressão e esclarecimento, ainda assim são densas até o limite da opacidade. Em consequência disso, não se torna possível entender um texto ao simplesmente correr os olhos sobre o mesmo. Nas palavras de Bosi (2003, p. 462) "Ler é colher tudo quanto vem escrito. Mas interpretar é eleger (ex-legere: escolher), na messe das possibilidades semânticas, apenas aquelas que se movem no enlaço da questão crucial: o que o texto quer dizer?" É através da interpretação que o leitor pode compreender de forma efetiva o sentido de um texto. 
Outro autor que contribui de forma importante para o estudo em questão é Richard Palmer que explica que uma obra literária não pode ser tratada como um objeto, um ser autônomo. É necessário encarar a obra não como um objeto, mas sim como uma obra. "Uma obra literária não é um objeto que compreendemos através da conceptualização ou da análise; é uma voz que devemos ouvir e 'ouvindo-a' (mais do que vendo-a) compreendemo-la" (Palmer, 2011, p.21). Por isso é fundamental que o intérprete tenha um método ou teoria que consiga decifrar desde a marca humana de uma obra até o seu significado mais denso. "A hermenêutica é o estudo da compreensão, é essencialmente a tarefa de compreender os textos" (Palmer, 2011, p.19). Através disso, a hermenêutica se torna essa teoria, essa ciência que busca uma compreensão adequada das obras enquanto obras.

Neste sentido, as concepções de Palmer e Bosi se assemelham, já que o segundo também pressupõe que em uma boa interpretação não se deve separar a obra do autor, porque um livro é fruto de motivações pessoais profundas, valores ideológicos e correntes culturais. Dessa forma, para poder decifrar um texto, o leitor não pode levar em consideração apenas o produto final, mas sim o desenvolvimento, o processo de construção desse texto. Para isso, ele deve reconstruir ou reviver em si mesmo o momento que levou o autor a escrever o livro. Ele precisa de um olhar intenso, demorado, que capte os diversos momentos coexistentes, de intenções íntimas, convenções ideológicas e/ou literárias que constituem o texto.

\section{A METAFICÇÃO}

Após compreender os pressupostos hermenêuticos e o posicionamento do leitor diante do texto para poder interpretá-lo, é necessário estudar a metaficção, que Linda Hutcheon (1984) denomina como uma "narrativa narcísica", ou seja, uma narrativa que expõe o próprio ato de narrar e investiga o processo de produção do texto. Uma ficção que prima pelo desvendamento do processo narrativo.

"Metaficção"... é ficção sobre ficção - isto é, ficção que inclui em si mesma um comentário sobre sua própria identidade 
narrativa e/ou lingüística. "Narcisista" - o adjetivo qualificativo escolhido aqui para designar essa autoconsciência textual não tem sentido pejorativo, mas principalmente descritivo e sugestivo, como as leituras alegóricas do mito de Narciso. (Hutcheon, 1984, p. 12, tradução nossa)

Gustavo Bernardo (2010) compreende a metaficção como um elemento estético autorreferente no qual a ficção duplica-se por dentro, falando de si mesma ou contento a si mesma. É um tipo de ficção que se dobra e se redobra de fora para dentro. A metaficção é uma ponte entre distintos níveis de ficção. Uma ponte interna na qual se pensa a ficção dentro da ficção (Bernardo, 2010, p. 39).

Um exemplo interessante utilizado por Bernardo para representar o processo que constitui a metaficção, são as babushkas - as bonecas tchecas que se encaixam umas dentro das outras. A criança abre a primeira boneca e encontra no seu interior outra semelhante e menor. Abre essa menor e encontra uma terceira, ainda menor, e assim por diante até a última, pequeníssima e de madeira maciça - que não se abre. Nesse momento a criança experimenta um sentimento confuso de decepção e júbilo. Se a última boneca não se abre, a criança não pode saber se há outra boneca, ainda menor, em seu interior. "Ora se há algo que ainda não sabemos, ainda temos uma boa razão para viver: procurar saber" (Bernardo, 2010, p. 31). Com a metafiç̧ão ocorre o mesmo: são diversas narrativas que impulsionam o leitor a querer ouvir o texto, a querer compreendê-lo intensamente.

Linda Hutcheon (1984) discute ainda, a questão da ficção, ao emaranhar-se à realidade. Isso ocorre precisamente quando o leitor se perde no enredo, ou não tem mais certeza do que é real ou fictício - aspecto recorrente em obras metaficcionais.

A literatura não é um discurso que possa ou deva ser falso (...)
é um discurso que, precisamente, não pode ser submetido ao
teste da verdade; ela não é verdadeira, nem falsa, e não faz
sentido levantar essa questão: é isso que define seu próprio
status de "ficção". (Todorov apud Hutcheon, 1991, p. 146)

Bernardo (2010) afirma que a ficção que atrai o leitor pela sua própria condição ficcional acaba levantando questões relevantes sobre as relações entre ficção e realidade e, além disso, traz à tona questões decisivas sobre a 
própria realidade. Patricia Waugh diz que os textos metaficcionais "não examinam apenas as estruturas fundamentais da ficção narrativa, eles também exploram a possível condição ficcional do mundo externo ao texto ficcional" (1984, p. 2, tradução nossa).

A reflexão teórica sobre a ficção - que surge a partir da leitura de obras metaficcionais -, se amplia para uma reflexão filosófica sobre a existência do indivíduo no mundo em que vive. A partir disso a metaficção representa uma busca de identidade, porém uma busca angustiante, já que para que o indivíduo possa dizer quem é, ele precisa sair de si próprio para poder se enxergar de fora para dentro, o que é impossível. Com isso, ele corre atrás da sua própria imagem como um cachorro que corre atrás do próprio rabo: para encontrá-la, precisa do outro, vale dizer, precisa de uma personagem (Bernardo, 2010, p. 183-189).

\section{VIDA E OBRA DE DANIEL GALERA}

Daniel Galera nasceu em 13 de julho de 1979, em São Paulo, e é um escritor e tradutor brasileiro, passou a maior parte da sua vida em Porto Alegre já que sua família vive no Rio Grande do Sul, e depois de adulto viveu alguns anos em São Paulo e Santa Catarina. Hoje mora, novamente, em solo gaúcho. O escritor começou a carreira publicando diversos contos e textos na internet no período de 1996 a 2001. Foi colunista do mailzine Cardosonline (COL), durante três anos, e lançou seus dois primeiros livros pelo selo independente Livros do Mal, criado em 2001 por ele, Daniel Pellizzari e Guilherme Pilla. Além de escrever prosa de ficção, Galera traduz autores de língua inglesa e ocasionalmente publica resenhas, ensaios e reportagens.

Suas primeiras publicações foram Dentes guardados (2001) e Até o dia em que o cão morreu (2003), ambos inicialmente publicados pela Livros do Mal e disponíveis on-line. Até o dia em que o cão morreu foi republicado, em 2007, pela Companhia das Letras, retirado da internet e adaptado para o cinema por Beto Brant e Renato Ciasca (Cão sem dono, 2007). Mãos de cavalo (2006) foi seu segundo romance, publicado pela Companhia das Letras, em 2006, e republicado em edições estrangeiras em Portugal, Itália, Argentina e França. 
O terceiro romance de Galera foi o vencedor do "Prêmio Machado de Assis de Romance", da Fundação Biblioteca Nacional, em 2008, e ainda classificou-se, em 2009, em terceiro lugar, no "Prêmio Jabuti". Cordilheira (2008) é ambientado em Buenos Aires e foi a primeira obra da coleção Amores Expressos, da Companhia das Letras, em que autores brasileiros escrevem romances ambientados em diversas cidades do mundo. A obra também ganhou uma publicação em Portugal.

Em 2010, Daniel Galera em parceria com o desenhista Rafael Coutinho lançou o livro Cachalote, narrativa em quadrinhos. Seu último romance publicado é Barba ensopada de sangue (2012), vencedor do Prêmio São Paulo de Literatura e $3^{\circ}$ lugar no Prêmio Jabuti na categoria Romance. A obra também foi publicada em outros países, como Alemanha, Portugal, Catalunha, Holanda, Espanha e Inglaterra.

\section{CORDILHEIRA}

Cordilheira conta a história de Anita van der Goltz Vianna, uma jovem escritora brasileira, que aos 29 anos, após publicar e obter um gigantesco sucesso com seu primeiro livro, sente um profundo incômodo não apenas com as obrigações que a fama Ihe proporciona, como dar entrevistas, participar de eventos literários e, principalmente, ter que falar com o público, mas também por que Anita renega a obra, não se identifica com a mesma e, inclusive, afirma detestá-la.

Órfã de mãe, com a perda do pai, o suicídio da melhor amiga, Anita decide abandonar o que promete ser uma brilhante carreira literária para seguir o sonho de ser mãe, entretanto, ao revelar seu desejo ao atual companheiro Danilo, a escritora percebe que ele abomina a ideia. Motivada a recomeçar, viaja a Buenos Aires para o lançamento da tradução de seu romance na Feira Internacional do Livro e lá conhece e se envolve emocionalmente com Holden, um misterioso fã argentino que adora a personagem principal de seu livro, Magnólia. 
A obscuridade de Holden se torna ainda mais acentuada quando ela descobre que ele e seus amigos, todos escritores, fazem parte de uma espécie de seita lítero-filosófica, cuja ideologia se baseia em substituir a vida pela invenção literária: eles escrevem livros, recriam a vida das personagens de suas narrativas, apropriando-se das características de sua personalidade e objetivos de vida. Cada membro da seita vive a vida de uma das personagens de seus livros. Holden leva isso a condições tão extremas que programa sua própria morte para ter o mesmo desfecho de sua personagem.

Ainda seduzida e quase obcecada pelo objetivo de ser mãe, Anita começa a conviver com os integrantes desse grupo e aos poucos percebe que Holden não a escolheu por acaso. Ele precisava de Magnólia - que no fim do livro assassina seu companheiro - para seu gran finale. Nessa rede de carências, em que Anita precisa de Holden para poder realizar sua fixação pela maternidade e ele precisa de Magnólia para o seu ritual de sacrifício, Anita acaba concordando com a ideia: "Pois bem. Uma morte, um nascimento. Uma troca justa" (Galera, 2008, p. 141).

\section{OS FRAGMENTOS DA METAFICÇÃO}

Após a contextualização acerca do enredo da obra Cordilheira, o artigo se propõe a exemplificar a metaficção que se revela no decorrer da narrativa. Desde o início de Cordilheira o leitor sabe que Anita é escritora e possui um livro publicado, com relevante sucesso. Pouco depois do início do segundo capítulo, quando a protagonista viaja a Buenos Aires, o público tem acesso ao último capítulo de Descrições da chuva, romance que ela escreveu. No desfecho da obra, Magnólia assassina seu atual companheiro Tomás, empurrando-o de um penhasco.

Ela agiu de acordo com todas as outras coisas e com as leis
que as regem, seu gesto foi belo e inevitável, e a criatura a seu
lado, aquele improvável arranjo de carne, despencou rente à
parede rochosa e foi tragada para sempre pela espuma e pelas
pedras. (Galera, 2008, p. 47)

Após alguns dias em Buenos Aires, Anita conhece Holden e, ao relacionar-se com ele, conhece seus amigos. Desde o princípio ela os acha 
incrivelmente estranhos: "Todos os amigos de Holden tinham lido o meu livro. Isso estava longe de ser a coisa mais estranha a respeito deles" (Galera, 2008, p. 86). Os amigos de Holden eram Juanjo, Jorge Parsifal, Vigo, Pepino e Silvia. No decorrer da narrativa percebe-se que todos são escritores e que recriam a vida de alguma personagem de suas obras.

Ao desenrolar da história Anita começa a receber alguns livros sem remetentes no apartamento de Holden. O primeiro livro chama-se Un cuarto oscuro en el fondo e é tão desagradável e repulsivo que ela não consegue continuar a leitura. "Parei de ler aí e joguei o livro longe. Quem poderia ter me enviado aquela porcaria, e por quê?" (Galera, 2008, p.94). Aos poucos, Anita percebe que Pepino, um dos integrantes da seita, é o responsável pelo envio dos livros. Contudo, Un cuarto oscuro en el fondo fora escrito por outra pessoa: "O Santiago Oyola do primeiro volume, aquele com o início intragável, era ninguém menos que o também intragável Juanjo" (Galera, 2008, p. 117).

Ao final do quinto capítulo, Anita recebe outra obra cujo título é Más que un sueño. Logo após a leitura dos primeiros parágrafos Anita já consegue conectar o enredo da obra com a personalidade e as preferências de outra amiga de Holden: Silvia. O conflito principal dessa obra centraliza-se em uma garota que descobre seu desejo por homens mais velhos - a particularidade da protagonista não surpreende Anita, pois Silvia também já havia demonstrado sua preferência definitiva por homens mais maduros.

Recapitulei o comportamento de Silvia nas poucas semanas em que convivemos e seu discurso na noite anterior. Fiquei admirada não com o que já sabia, que cada um no grupinho de Holden tinha seu livro e seu personagem a ser desempenhado na vida real, mas com o alcance dessa prática, pelo menos no caso de Silvia. Ela levava sua personagem muito a sério. (Galera, 2008, p. 112)

El gran hotel del universo, de Juan Jesús Terragno, é o livro que representa a vida de Vigo, porém ele é um personagem secundário da obra. $O$ número de semelhanças entre o cadeirante da ficção e o da vida real, segundo Anita, é assustador. Ambos são carecas, barbudos e tem o "saudável" hábito de andarem apressados pelas ruas de uma cidade agarrados aos parachoques de automóveis. O Vigo de El gran hotel del universo tentando proteger 
a filha da aproximação de uma Primavera sinistra. O Vigo, amigo de Holden, criando uma filha cujo nome é Primavera. Em um fragmento da história Pepino faz questão de apresentá-la a Anita, para mostrar até que ponto Vigo foi capaz de chegar por devoção à sua personagem:

- Ela existe única e exclusivamente porque foi imaginada e convertida em letra impressa num livro de ficção - disse Pepino, erguendo Primavera no colo para atravessar um trecho tumultuado da calçada. Entendi na hora, com certo mal-estar, o que ele pretendia insinuar com isso. Para tornar-se seu personagem, um homem tinha ido ao ponto de gerar uma criança. (Galera, 2008, p. 137-138)

A obra de Jorge Parsifal não é mencionada separadamente, ou de forma exclusiva, como as outras. Há um trecho em que ele aparece "com um olho roxo, uma lente dos óculos rachada e a cara toda desmontada" (Galera, 2008, p. 128). Ao perguntar o que havia ocorrido, Anita inteira-se de que o livro - cujo título não é mencionado - e a personagem que ele representa é a de um homem que trabalha à noite em uma sex shop onde se alugam cabines para assistir a filmes pornográficos: "O emprego dele, ou melhor, de seu personagem, era fazer a limpeza dessas cabines. Na noite anterior, Parsifal tinha brigado com um dos clientes num episódio que não vale a pena narrar" (Galera, 2008, p. 128).

Assim como a anterior, a obra de Pepino não possui muito espaço na narrativa. Ela chama-se La película blanca, e ele mesmo conta o enredo para Anita:

- É sobre um cara que vai ao litoral brasileiro filmar um curtametragem, é estuprado por um sujeito que Ihe dá carona e... ele empacou. [...] Uma vez fui a uma praia brasileira passar férias. Capão da Canoa. Foi em 1993 ou 94. Peguei carona com um sujeito depois de uma festa. Ele pôs a mão na minha perna, coisa e tal. Não aconteceu nada tão grave, mas foi um episódio que me atormentou, por uma série de motivos. (Galera, 2008, p. 135-136)

Ao deparar-se com o livro La conjuración sagrada, Anita descobre o verdadeiro nome do atual namorado: Holden é, na verdade, Diego Parisi. Diego leva a ideologia tão à risca que se apropriara, inclusive, do nome de sua personagem. A história de ambos também é incrivelmente semelhante: possuem um emprego em uma repartição pública, à noite transformam-se em 
libertinos que justificam suas atitudes "com argumentos filosóficos de butique e tiradinhas nietzschianas" (Galera, 2008, p. 118) e fazem parte de uma seita que discute textos de sua própria autoria.

A surpresa ocorre, porém, quando Anita lê a última parte do livro: o protagonista decide que quer fundar uma religião e inicialmente convence seus amigos a estudarem textos sobre religiões do mundo todo. Contudo, aos poucos, ele começa a enlouquecer ficando obsessivo pela realização de um sacrifício, como na religião dos astecas. Assim, seus amigos começam a se afastar, pois embora ele se ofereça como a primeira vítima, ninguém se dispõe a matá-lo. Galera (2008) é cuidadoso ao costurar os fios da ficção. O final trágico e aparentemente sem sentido de Tomás - companheiro de Magnólia é um detalhe precioso que se encaixa perfeitamente com o final de Holden - 0 fim que ele deseja. Aí se justifica a escolha por Anita.

É importante ressaltar a sutileza de Galera (2008, p. 118) ao realmente terminar a história de La conjuración sagrada. No final do livro há um prólogo em que o protagonista, já idoso, recorda com certo menosprezo as suas ambições juvenis. Contudo, nas últimas linhas abre-se a possibilidade de que 0 narrador não seja confiável. "Descobrimos que o José Holden idoso, agora um escritor de renome, está dando uma entrevista. Há indícios de que ele esteja enrolando o jornalista. Somos levados a crer que sua religião secreta continuou existindo e ainda existe" (Galera, 2008, p. 118).

Embora a personagem Anita desde o princípio renegue a obra que escreveu e não se identifique com a mesma, aos poucos a protagonista começa a agir como Magnólia. Evidentemente isso é consequência do estímulo dos membros da seita: "- Você acha que devo ir embora? Eu poderia sumir agora mesmo." Ela pergunta a Pepino, e ele responde: “- Não sei. Mas recomendo que comece a pensar da seguinte forma: o que Magnólia faria?" (Galera, 2008, p. 139) Porém independente disto, ficção e realidade se aproximam de tal forma que se torna difícil distinguir uma da outra. Anita, após engravidar de Holden, sente um desejo tão profundo de ir embora, ser livre, que faria qualquer coisa para poder conseguir isso. O mesmo anseio de Magnólia, agora é sentido por Anita: 


\begin{abstract}
A solidão da minha personagem era análoga à solidão que eu própria sentia agora, e seu desejo secreto, inconfessável, nunca explicitado [...] era muito, muito semelhante ao meu desejo secreto, inconfessável e nunca explicitado de dar um jeito qualquer de livrar-me logo da farsa em que havia me metido para finalmente ficar livre, sozinha ao meu modo, dona exclusiva da vida que poderia ter com meu filho dali para a frente. (Galera, 2008, p. 118)
\end{abstract}

Neste trecho é possível ver o momento em que a ficção e a realidade já não podem mais ser, ao total, separadas, sendo que uma é parte da outra. Embora não percebesse, Anita estava começando a pensar e quem sabe até agir como Magnólia. Independentemente do que a motiva a fazê-lo, o interessante é observar que neste ponto a metaficção se evidencia, pois o leitor tem consciência da personagem Anita e da personagem criada por Anita Magnólia, a ficção dentro da ficção.

\title{
7. CONSIDERAÇÕES FINAIS
}

Após os estudos realizados pode-se perceber que o texto metaficcional constitui um discurso mais complexo, que exige uma profunda entrega por parte do leitor. Ou seja, ao simplesmente correr os olhos sobre o texto, o leitor não tem a real interpretação do mesmo. Ele não compreende, de fato, o que o autor quer dizer. Além disso, a metaficção pode ser pensada como uma forma de produção de conhecimento já que o leitor busca no texto o sentido da sua própria existência.

Ao interpretar o enredo literário de forma crítica, levando em consideração os conceitos estudados, percebe-se que a obra agrega conhecimento à narrativa já que o leitor busca um sentido no texto. É o desejo de traduzir o texto que desencadeia a produção de conhecimento. Existe ainda uma busca de identidade do leitor com a obra. Isso é justificado, nas palavras de Bernardo, quando ele afirma que essa busca é angustiante visto que o indivíduo não consegue sair de si mesmo, e por isso precisa da personagem. Essa é uma possibilidade interpretativa do que ocorre em Cordilheira: Anita assim como Holden e seus amigos - escreve uma obra por que é através da visualização de uma personagem que ela consegue se enxergar de fora para dentro. É um processo complexo, porém gratificante. 
O mesmo se dá na literatura. Um leitor atento, que vê na narrativa uma possibilidade de maturação, pensa a obra enquanto repensa seus próprios conceitos e valores pessoais. Usa a personagem como um espelho em que se refletem as semelhanças ou diferenças da sua personalidade. Ao enxergar-se nesta ótica, o leitor reconsidera seus traços mais íntimos, a fim de lapidar a si próprio. Em outras palavras, a presença da metafiç̧ão evidencia uma singularidade da natureza literária: o leitor possui uma relação íntima com a literatura baseada num compromisso mútuo. A literatura se apresenta supérflua ou mesmo sem sentido para o leitor desatento que, ao não conseguir decifrá-la, poderá sentir desdém ou até desprezo. Entretanto um leitor dedicado, que se propõe a realizar um processo de escuta da narrativa, recebe como recompensa a percepção de uma obra verdadeiramente complexa e sentirá fascínio em desvendar as suas minúcias e abismos.

\section{REFERÊNCIAS}

BERNARDO, Gustavo. O livro da metaficção. Rio de Janeiro: Tinta Negra, 2010.

BOSI, Alfredo. A interpretação da obra literária. In: Céu, inferno: ensaios de crítica literária e ideologia. São Paulo: Duas Cidades; Editora 34, 2003.

HUTCHEON, Linda. Narcisistic narrative: the metaficcional paradoxe. New York: Methuen, 1984. Imago, 1991.

Poética do pós-modernismo: história, teoria, ficção. Rio de Janeiro: GALERA, Daniel. Cordilheira. São Paulo: Companhia das Letras, 2008.

. Rancho carne blog [Internet]. Porto Alegre: Daniel Galera. Disponível em http://ranchocarne.org/. Acesso em: 27 set. 2014.

PALMER, Richard E. Hermenêutica. Lisboa: Edições 70, 2011.

WAUGH, Patricia. Metafiction: the theory and practice of self-conscious fiction. Londres: Routledge, 2003. 